\title{
Effect of Amphotericin B on the Incorporation of Neocarzinostatin into Human Gastric Cancerous Tissues
}

\author{
Ichiro Nakazawa, Eietsu Ouchi, Nakao Ishida, ${ }^{*}$ KenJI \\ OUCHI $\dagger$ and KeIKICHI WAGAI $\dagger$ \\ The Third Department of Internal Medicine and *Department of \\ Bacteriology, Tohoku University School of Medicine, Sendai 980, \\ and †Department of Surgery, Kesennuma Public Hospital, \\ Kesennuma 988
}

\begin{abstract}
Nakazawa, I., OUchi, E., Ishida, N., Ouchi, K. and Wagai, K. Effect of Amphotericin $B$ on the Incorporation of Neocarzinostatin into Human Gastric Cancerous Tissues. Tohoku J. exp. Med., 1978, 124 (1), 97-98 — AmB/NCS combination therapy against cancer was evaluated. Seven gastric cancer and 2 gastric polyp cases were treated in this manner and in addition 2 gastric cancer patients were treated with NCS alone, to serve as the control. AmB dissolved in glucose solution was administered intravenously as was NCS, which was given at the onset of gastric surgery. Lesion tissues and healthy tissues were collected from each patient and the NCS titers measured by bioassay. It was shown in the majority of the gastric cancer cases that the NCS levels in the lesion tissues were substantially higher than in the surrounding normal tissues, whereas in the gastric polyp and the gastric cancer patients who received NCS alone, no significant differences were found between the tissues. - amphotericin B; neocarzinostatin; gastric cancer; chemotheraphy
\end{abstract}

Neocarzinostatin (NCS) was discovered by Ishida et al. in 1965 and is the first antibiotic protein to be used in human cancer chemotherapy. Amphotericin (AmB) is a polyene antibiotic which increases cellular permeability. In this study, the combined effects of $\mathrm{AmB}$ and NCS were tested by measuring the concentration of NCS in the cancerous tissues of gastric cancer patients.

Materials and Methods. Seven gastric cancer and 2 gastric polyp patients were given antihistaminics and antipyretica $4.5 \mathrm{hr}$ before surgery. Half an hour later these patients were given intravenously $2 \mathrm{mg}$ of $\mathrm{AmB}$ dissolved in $500 \mathrm{ml}$ of $5 \%$ glucose solution over a period of $4 \mathrm{hr}$. Then, simultaneously with the start of gastric surgery, $2 \mathrm{mg}$ of NCS dissolved in $250 \mathrm{ml}$ of $5 \%$ glucose solution were administered intravenously over one hr. Two gastric cancer patients who did not receive $\mathrm{AmB}$ were also treated in this manner. Immediately after the stomach was taken out, the cancer lesion and surrounding normal tissues from each patient were collected and stored at $-20^{\circ} \mathrm{C}$. Bioassays using Sarcina lutea ATCC ('Toriyama et al. 1975) were performed to measure the titer of NCS present in each tissue.

Results and Discussion. As shown in Table 1, in 5 of the 7 cancer cases that received combination therapy, the NCS titers of the cancer tissues were higher by $10 \%$ to $60 \%$ than those of the normal tissues surrounding the lesions. It is interesting that the NCS levels

Received for publication, October 1, 1977. 
TABLE 1. Content of NCS in human gastric cancerous, polypous and normal tissues

A. $\mathrm{AmB}+\mathrm{NCS}$ combined therapy

\begin{tabular}{lcccccc} 
a) Gastric cancer & & \multicolumn{3}{c}{ NCS content of tissues } \\
\cline { 4 - 6 } \multicolumn{2}{c}{ Case } & Age & Sex & Cancer tissue & Normal tissue & Ratio* \\
& & & & & & \\
1 & M.H. & 44 & Female & $0.56 \mu \mathrm{g}$ & $0.35 \mu \mathrm{g}$ & 1.60 \\
2 & N.K. & 76 & Male & 0.84 & 0.61 & 1.38 \\
3 & H.F. & 64 & Female & 0.64 & 0.50 & 1.28 \\
4 & Y.o. & 58 & Male & 0.67 & 0.57 & 1.18 \\
5 & T.K. & 57 & Male & 0.44 & 0.40 & 1.10 \\
6 & N.S. & 60 & Male & 0.47 & 0.45 & 1.04 \\
7 & M.I. & 64 & Male & 0.53 & 0.53 & 1.00
\end{tabular}

b) Gastric polyp

Polyp tissue Normal tissue

$\begin{array}{lllllll}1 & \text { K.o. } & 74 & \text { Female } & 0.69 & 0.64 & 1.07 \\ 2 & \text { T.O. } & 61 & \text { Male } & 0.33 & 0.37 & 0.89\end{array}$

B. NCS treatment alone

a) Gastric cancer

$\begin{array}{lllllll}1 & \text { I.O. } & 53 & \text { Female } & 0.36 & 0.36 & 1.00 \\ 2 & \text { S.M. } & 71 & \text { Male } & 0.25 & 0.24 & 1.04\end{array}$

* Ratio: NCS content of lesion tissue/NCS content of normal tissue.

in the lesion and control tissues of the benign cases (gastric polyp) were similar. Presant et al. (1976) reported a combination therapy using AmB and BCNU. In the present study we used smaller amounts of $\mathrm{AmB}$ in order to reduce toxicity, nevertheless our results mentioned above strongly suggest the positive effect of AmB/NCS combination therapy against gastric cancer.

\section{References}

1) Ishida, N., Miyazaki, K., Kumagai, K. \& Rikimaru, M. (1965) Neocarzinostatin, an antitumor antibiotic of high molecular weight; isolation, physicochemical properties and biological activities. J. Antibiotics, Ser. A, 18, 68-76.

2) Presant, A., Klahr, C., Oleander, J. \& Gatwood, D. (1976) Amphotericin B plus 1,3BIS (2-chloroethyl)-1-nitrosourea (BCNU-NSC No. 409962) in advanced cancer. Cancer, 38, 1917-1921.

3) Toriyama, K., Fujita, H. \& Ishida, N. (1975) Absorption, distribution and excretion of neocarzinostatin (NCS) in mice after oral administration. J. Antibiotics, 28, 64-72. 